\title{
A double-blind randomized controlled trial showing the analgesic and anesthetic properties of lidocaine $E$ to be equivalent to those of ropivicaine and bupivacaine in carpal tunnel release surgery
}

\author{
A Pressman MD, G Doumit MD, O Rosaeg MD FRCP, M Bell MD FRCS
}

\begin{abstract}
A Pressman, G Doumit, O Rosaeg, M Bell. A double-blind randomized controlled trial showing the analgesic and anesthetic properties of lidocaine $\mathrm{E}$ to be equivalent to those of ropivicaine and bupivacaine in carpal tunnel release surgery. Can J Plast Surg 2005;13(4):173-176.
\end{abstract}

In a three-phase trial, the anesthetic properties of lidocaine, bupivacaine and ropivicaine were compared in carpal tunnel release surgery. In phase I, two groups of 25 sequential patients were injected with either lidocaine plain $2 \%$ or lidocaine $2 \%$ with adrenaline $1: 100,000$ (E), as the local anesthetic for outpatient carpal tunnel release surgery. Subjective injection pain, postoperative pain at $2 \mathrm{~h}$ increments and the number of analgesic pills taken were recorded. During the first postoperative hours, outcome measures were superior in the lidocaine E group.

In phase II, a double-blind randomized design compared 42 patients injected with either lidocaine $\mathrm{E}$ or a combination of lidocaine $\mathrm{E}$ and bupivacaine. Postoperative pain scores and analgesic pills taken were compared using nonparametric statistical tests. During the first $4 \mathrm{~h}$ there was a slight benefit in the duration of the anesthetic and fewer pain pills were used in the bupivacaine group.

Phase III was a randomized double-blind comparison of ropivicaine and lidocaine E $2 \%$ in 72 patients. There was a slight decrease in pain scores and fewer analgesic pills required during the first $6 \mathrm{~h}$ in the ropivicaine group.

Lidocaine plain $2 \%$ provided significantly inferior analgesic and anesthetic properties compared with lidocaine E 2\%, bupivacaine or ropivicaine. Sequential randomized comparisons between lidocaine $\mathrm{E}$ and bupivacaine and ropivicaine showed clinical equivalence. The present study showed lidocaine E 2\% to be a satisfactory and comparatively cost-effective anesthetic for outpatient carpal tunnel surgery.

Key Words: Carpal tunnel surgery; Local anesthesia
Un essai aléatoire et contrôlé à double insu démontre que les propriétés analgésiques et anesthésiques de la lidocaïne $\mathrm{E}$ sont équivalentes à celles de la ropivicaïne et de la bupivacaïne pour le dégagement chirurgical du canal carpien

Pendant un essai en trois phases, les propriétés anesthésiques de la lidocaïne, de la bupivacaïne et de la ropivicaïne ont été comparées dans le cadre du dégagement chirurgical du canal carpien. Pendant la phase I, deux groupes de 25 patients séquentiels ont reçu une injection de lidocaïne simple à $2 \%$ ou de lidocaïne à $2 \%$ associée à de l'adrénaline 1:100 000 (E), comme anesthésique local pour dégager leur canal carpien par voie chirurgicale sans hospitalisation. La douleur subjective à l'injection, la douleur postopératoire par intervalles de deux heures et le nombre de comprimés analgésiques consommés ont été consignés. Pendant les premières heures postopératoires, les mesures d'issue étaient supérieures au sein du groupe prenant de la lidocaïne $\mathrm{E}$.

Pendant la phase II, un essai aléatoire à double insu a permis de comparer 42 patients à qui on avait injecté soit de la lidocaïne $\mathrm{E}$, soit une association de lidocaïne $\mathrm{E}$ et de bupivacaïne. Les indices de douleur postopératoire et les comprimés analgésiques consommés ont été comparés au moyen de tests statistiques non paramétriques. Pendant les quatre premières heures, on remarquait un léger avantage dans la durée de l'effet anesthésique et un moins grand nombre de comprimés utilisés au sein du groupe prenant de la bupivacaïne.

La phase III était une comparaison aléatoire à double insu de la ropivicaïne et de la lidocaïne E à $2 \%$ chez 72 patients. On remarquait une légère diminution des indices de douleur et un moins grand nombre de comprimés analgésiques nécessaires pendant les six premières heures au sein du groupe prenant de la ropivicaïne.

La lidocaïne simple à $2 \%$ avait des propriétés analgésiques et anesthésiques considérablement inférieures à la lidocaïne $\mathrm{E}$ à $2 \%$, à la bupivacaïne ou à la ropivicaïne. Des comparaisons aléatoires séquentielles entre la lidocaïne $\mathrm{E}$, la bupivacaïne et la ropivicaïne démontraient une équivalence clinique. La présente étude révèle que la lidocaïne $\mathrm{E}$ à 2 \% est un anesthésique satisfaisant et comparativement rentable pour le dégagement chirurgical du canal carpien sans hospitalisation.
Significant median nerve compression in the carpal canal

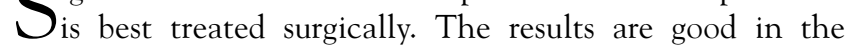
majority of cases, with outcome being largely dependent on the pre-existing damage to the median nerve (1). This surgery is now most often performed under local anesthesia on an outpatient basis. The present prospective randomized controlled trial compared the properties of the three most commonly used local anesthetics.

\section{Phase I}

\section{PATIENTS AND METHODS}

All patients in this series had a typical history of a carpal tunnel syndrome lasting longer than three months and a positive clinical examination including measured weakness of the abductor pollicis brevis muscle (2). Fifty-seven per cent of the referred patients in phase I had preoperative confirmatory electromyography performed. 
Patients were excluded if they had an allergy to codeine, were taking narcotic medications, nonsteroidal anti-inflammatory drugs or major tranquilizers for concurrent medical illness. Two nonrandomly assigned sequential groups of 25 patients, with an established diagnosis of carpal tunnel syndrome, had a carpal tunnel release using lidocaine $2 \%$ with adrenaline (E) or lidocaine $2 \%$ plain $(\mathrm{P})$.

\section{Injection technique}

A 25-gauge needle was inserted at the distal wrist crease and was advanced slowly, injecting vertically downward against the resistance of the ligament until free flow of the anesthetic occurred. Approximately $1 \mathrm{~mL}$ of anesthetic was placed beneath the ligament. The needle was then withdrawn and advanced distally along the plane of the fourth digit, injecting approximately $4 \mathrm{~mL}$ or $5 \mathrm{~mL}$ subcutaneously. The incision was begun no sooner than 5 min after the injection had been done. The median nerve was decompressed by a longitudinal incision in the proximal palm in line with the axis of the fourth finger, approximately $3 \mathrm{~cm}$ in length. The superficial palmar fascia, transverse palmar ligament and antebrachial fascia were divided. The skin was sutured with nonabsorbable sutures and a sterile gauze compression dressing was applied.

Patients were given written instructions to complete the data sheets. Pain was graded with the use of a visual analogue scale (VAS). Patients scored maximum pain in $2 \mathrm{~h}$ intervals as well as pain at injection. The number of pain pills used was recorded during the first $10 \mathrm{~h}$, at $2 \mathrm{~h}$ intervals. All patients were given prescriptions for Tylenol \#3 tablets (Ortho-McNeil, USA). Patients were instructed to take one to two pills every $4 \mathrm{~h}$, as needed for pain. Questionnaires were returned at the first postoperative visit.

\section{Phase II}

Forty-two patients who had carpal tunnel release comprised the randomized double-blind study. The previous exclusion criteria were applied. Using a random number table, each patient received either $6 \mathrm{~mL}$ of lidocaine E $2 \%$ or $3 \mathrm{~mL}$ of lidocaine $\mathrm{E} 2 \%$ plus $3 \mathrm{~mL}$ of bupivacaine $0.5 \%$. All solutions were clear. Both the surgeon and the patient were blinded to the solution being used. Data sheets were then given to the patient and were collected at the first postoperative visit.

\section{Phase III}

Seventy-two patients with a carpal tunnel release were studied in a prospective randomized double-blind manner. The same exclusion criteria were applied. Using a random number table, each patient received either $6 \mathrm{~mL}$ of lidocaine E $2 \%$ or $6 \mathrm{~mL}$ of ropivicaine $0.5 \%$. Both the surgeon and the patient were blinded to the solution that was used. Data sheets given to the patient were collected on the first postoperative visit.

\section{Phase I}

The data forms from the two sequential series of 25 patients were collected with a similar response rate of 23 of 25 (92\%). There were no intraoperative or postoperative complications. The authors prospectively selected several outcome measures including infiltration pain, a lapsed time before pain increasing from the baseline, pain scores at $2 \mathrm{~h}$ intervals, the time at which the first analgesic pill was used and the total number of analgesics used in $10 \mathrm{~h}$.
Descriptive statistics were performed on the phase I data. Differences between groups were identified. After review of these data, sample size calculations were carried out to determine a 50\% difference between aesthetic agents, given a study group with similar SDs. The authors hypothesized that a similar magnitude of difference to that between lidocaine $\mathrm{P}$ and lidocaine $\mathrm{E}$ would be apparent at the junction of the duration of activity of an anesthetic agent.

Sample size was based on calculated SDs, an alpha of 0.05 and a beta of 0.80 . After completion of phase II, the study size was increased to detect a difference of $25 \%$ between groups. After review of the phase I data, the prospectively selected outcome measure 'elapsed time before pain increasing from the baseline' was amended to 'elapsed time before pain increased to a value greater than $2.0 \mathrm{~cm}$ on the VAS'.

Statistical comparisons were made among each of the three lidocaine E groups (phases I to III) and no significant differences were found. The demographic data of these groups were further evaluated to show a minimal trend to decreased analgesic requirements in women and younger patients in the phase II lidocaine $\mathrm{E}$ data. The lidocaine $\mathrm{P}$ data series (23 patients) was then compared with the entire lidocaine E data phases I to III (73 patients). Although no significant differences existed among groups, this segment of the present study was not randomized and, thus, the authors felt that the increased sample size of the latter group would help to reduce confounding differences among lidocaine E groups.

The comparison revealed that postoperative pain was substantially greater in patients who had received lidocaine $\mathrm{P}$ at $2 \mathrm{~h}$, $4 \mathrm{~h}$ and $6 \mathrm{~h}(\mathrm{P}=0.01, \mathrm{P}=0.001$ and $\mathrm{P}=0.26$, respectively $)$. Elapsed time until pain was greater than $2.0 \mathrm{~cm}(\mathrm{P}=0.01)$ and postoperative analgesic pill use $(\mathrm{P}=0.12)$ were also improved in the lidocaine $\mathrm{E}$ group. It is important to note that the trend toward analgesic differences extended even beyond these time intervals.

\section{Phase II}

Responses to the postoperative questionnaire were obtained in 18 of $21(86 \%)$ and 19 of $21(90 \%)$ subjects in the randomized bupivacaine and lidocaine groups, respectively. The data were collected and averaged for these groups. No statistically significant differences were noted in age or sex distributions, the responses to postoperative pain or analgesic use.

A trend toward decreased pain postoperatively was seen in the bupivacaine group (Figure 1). The time until the first pain pill was taken showed a similar trend $(\mathrm{P}=0.14)$, in which the bupivacaine group required their first analgesic at $7.4 \mathrm{~h} \mathrm{com-}$ pared with $6.8 \mathrm{~h}$ in the lidocaine E group (Figure 2).

Because the intergroup variance was smaller than hypothesized, the size of phase III was increased to detect a smaller difference between groups (25\% from the lidocaine E group rather than $50 \%$ ).

\section{Phase III}

The response rate for the ropivicaine group was 30 of 36 (83\%) and 32 of 36 (89\%) subjects for the lidocaine E group. There were no statistically significant differences in age or sex distribution or in sex-specific results.

The results show improved anesthetic and analgesic properties in the first $6 \mathrm{~h}$ (Figure 1). Differences on the VAS between $0.5 \mathrm{~cm}$ and $1.6 \mathrm{~cm}(\mathrm{P}=0.04)$ were seen between groups at $4 \mathrm{~h}$ and $1.4 \mathrm{~cm}$ and $2.9 \mathrm{~cm}(\mathrm{P}=0.02)$ at $6 \mathrm{~h}$ postoperatively. By $8 \mathrm{~h}$ 


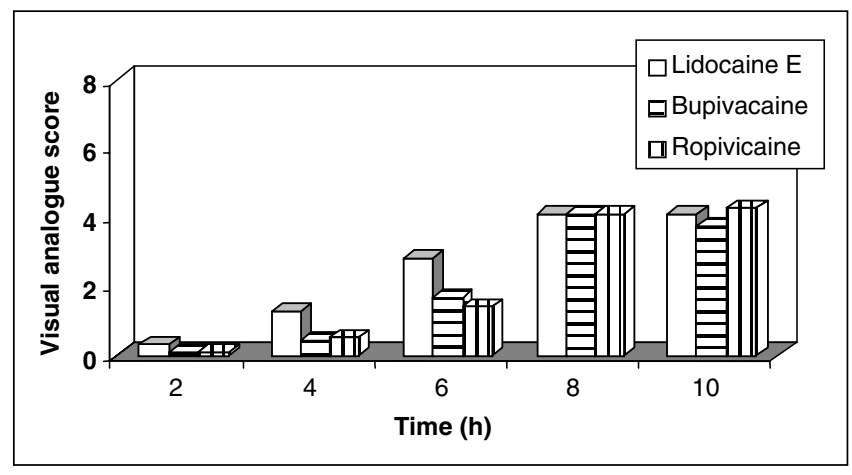

Figure 1) Visual analogue pain score versus time for lidocaine, bupivacaine and ropivicaine. Lidocaine E Lidocaine $2 \%$ with adrenaline $1: 100,000$

to $10 \mathrm{~h}$, there were no longer significant differences. The time that had elapsed in each group before pain increased beyond 2.0 $\mathrm{cm}$ on the VAS was $6.4 \mathrm{~h}$ and $7.2 \mathrm{~h}(\mathrm{P}=0.23)$ in favour of ropivicaine. With respect to pill usage, no noteworthy differences were seen except in pill consumption at $6 \mathrm{~h}(\mathrm{P}=0.05)$, in which there was $50 \%$ increased consumption in the lidocaine $\mathrm{E}$ group (Figure 2).

\section{DISCUSSION}

Carpal tunnel syndrome was first described by Paget in 1853, and the first carpal tunnel decompression was performed by Learmonth in 1933 (Kulick [1]). It was not until Phalen popularized carpal tunnel surgery in the 1950s and the use of local anesthetics in $1966 \mathrm{did}$ the procedure become common place (3-6).

Current literature agrees uniformly on the common features of this condition by examination of patient history and special tests. Nonoperative modalities of treatment are variably effective and include activity modification, splints and injections. Operative treatment, if performed in a timely fashion, is successful with minimal morbidity and excellent outcomes. The present study was designed to investigate perioperative pain in outpatient carpal tunnel surgery performed with several common local anesthetic agents.

Local anesthetics prevent a rapid influx of sodium ions across the axolemma. This reduced ion flux dampens the action potential and prevents propogation of the electrical impulse (7). The authors had observed slower onset and increased pain with $0.5 \%$ bupivacaine. The combination of $0.5 \%$ bupivacaine with xylocaine E $2 \%$ was therefore chosen to avoid these two particular problems.

There are a number of interesting articles in the literature related to carpal tunnel release with local anesthesia (8). Baguneid et al (7) conducted a survey to investigate the use of local anesthetics in carpal tunnel surgery. With a response rate of $65 \%$, they found that $35 \%$ of 51 orthopedic surgeons routinely used local anesthesia, $41 \%$ used local anesthesia in 'unfit patients' and $22 \%$ used other anesthetic approaches. Some authors (9) suggest that injection of local anesthetic can inadvertently puncture the median nerve, and reported a median nerve injury subsequent to a local steroid injection at the wrist. However, despite this concern, there did not appear to be clinical consequences to injection of local anesthetic at the wrist in 126 patients (9).

Phase I represented a pilot project. An examination of these data led the authors to conclude that the two best outcome

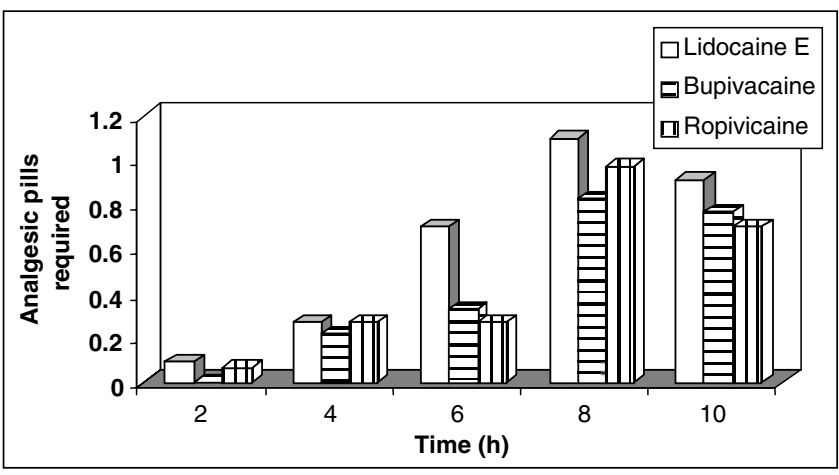

Figure 2) Analgesic pills required versus time in patients who received lidocaine 2\% with adrenaline 1:100,000 (E), bupivacaine or ropivicaine

measures would be the time elapsed before requiring analgesic pills and the time elapsed before the average pain on the VAS increased to a value of greater than two of $10(2.0 \mathrm{~cm})$. It is apparent from phase 1 data that patients tended to score pain in the $0 \mathrm{~cm}$ to $2.0 \mathrm{~cm}$ range or in the $5.0 \mathrm{~cm}$ to $10.0 \mathrm{~cm}$ range on the VAS. In addition, the time elapsed before requiring analgesic pills may provide some indication as to the duration of activity of the anesthetic agent.

Analysis of the phase I data indicated that pain and analgesic requirements were significantly higher in the lidocaine $\mathrm{P}$ group than in the lidocaine $\mathrm{E}$ group. In fact, the average pain had already reached $2.0 \mathrm{~cm}$ at $2 \mathrm{~h}$ postoperatively. The lidocaine P results may help to explain the poor results obtained with postoperative analgesia in previous studies (10).

The interpretation of the data in phases II and III is more difficult. Here, trends toward statistical significance (phase II) and improved postoperative pain at $4 \mathrm{~h}$ and $6 \mathrm{~h}$ (phase III) can be seen. However, the magnitude of the pain identified at $4 \mathrm{~h}$, was $0.5 \mathrm{~cm}$ for both bupivacaine and ropivacaine compared with between $1.3 \mathrm{~cm}$ and $1.6 \mathrm{~cm}$ for the lidocaine groups (phases II and III, respectively). At $6 \mathrm{~h}$, a more clinically significant result can be noted. Here, average VAS reports for pain were $1.7 \mathrm{~cm}$ and $1.4 \mathrm{~cm}$ for bupivacaine and ropivicaine, respectively; however, for lidocaine E, pain results were $2.6 \mathrm{~cm}$ and $2.0 \mathrm{~cm}$ for phases II and III, respectively (Figure 1). The corresponding lidocaine $\mathrm{P}$ pain value was $3.9 \mathrm{~cm}$ for phase I. Between $8 \mathrm{~h}$ and $10 \mathrm{~h}$, the groups began to converge, although a slightly lower average pain score was noted for bupivacaine. Trends were noted such that the average time that had elapsed before pain increased to greater than $2.0 \mathrm{~cm}$ ranged from $7.2 \mathrm{~h}$ to $7.4 \mathrm{~h}$ for bupivacaine/ropivicaine and $6.3 \mathrm{~h}$ to $6.4 \mathrm{~h}$ for phase II and III lidocaine E data.

Interpretation of the analgesic requirement data was complicated by the fact that between $4 \%$ and $22 \%$ of the patients who had surgery did not require analgesic medications in the first $10 \mathrm{~h}$ postoperatively. This complicated the calculations for elapsed time until analgesics were required. The authors did not initially appreciate that a significant number of patients might not require analgesics. As a result, for these calculations, all patients were considered to have consumed an analgesic pill at $12 \mathrm{~h}$, if they had not previously done so. Correspondingly, the authors did not find this data as useful as had been expected.

Phase I illustrated different analgesic usage patterns in the lidocaine $\mathrm{P}$ group compared with the lidocaine $\mathrm{E}$ group. The time that elapsed until the first analgesic was consumed was 
dramatically lower $(\mathrm{P}=0.01)$, and requirements at $2 \mathrm{~h}$ and $4 \mathrm{~h}$ were dramatically increased $(\mathrm{P}=0.01$ and $\mathrm{P}=0.12$, respectively). It is also interesting that, although there was a trend toward overall increased analgesic use, at $10 \mathrm{~h}$, fewer pills were consumed by the lidocaine $\mathrm{P}$ group $(\mathrm{P}=0.05)$. The authors hypothesized that this resulted from the increased usage in the previous $8 \mathrm{~h}$. In both phase II and III, a difference in pill requirements was noted at $6 \mathrm{~h}$ between lidocaine $\mathrm{E}$ and bupivacaine/ropivicaine.

The interpretation of the results at first glance parallels the known half-lives of the various anesthetic agents; however, it was noteworthy that pain appeared to plateau at $3.5 \mathrm{~cm}$ to $4.1 \mathrm{~cm}$ at $10 \mathrm{~h}$. Injection pain was reported to be $4.5 \mathrm{~cm}$ on average. Surgery was well tolerated by all groups and only one patient (in the lidocaine $\mathrm{P}$ group - phase I) required an additional intraoperative dose of anesthetic. On average, 2.8 analgesic pills were used (excluding the lidocaine $\mathrm{P}$ group). The first pill was taken at an average of $6.9 \mathrm{~h}$ postoperatively (excluding the lidocaine $\mathrm{P}$ group) (Figure 2).

Ropivicaine is an amide anesthetic, which provides a reversible blockage of impulse propagation by impairing sodium channels. It possess an inherent vasoconstrictive properties, a $8 \mathrm{~h}$ to $12 \mathrm{~h}$ duration of activity and an unfavourably slow onset of activity, being $10 \mathrm{~min}$ to $25 \mathrm{~min}$. The present study did not show ropivicaine to have superior anaesthetic or analgesic properties to bupivacaine. Of note, there is a substantial difference in cost among lidocaine, bupivacaine and ropivicaine in Canada.

The present study did not clearly show bupivacaine or ropivicaine to be clinically superior to lidocaine $E$. The

\section{REFERENCES}

1. Kulick RG. Carpal tunnel syndrome. Orthop Clin North Am 1996;27:345-54.

2. Bigelow E, Bell M. Carpal tunnel syndrome: A new objective evaluation technique. Can J Plast Surg 1998;6:99-103 .

3. Dupont C, Ciaburro H, Prevost Y, Cloutier G. Hand surgery under wrist block and local infiltration anesthesia, using an upper arm tourniquet. Plast Reconstr Surg 1972;50:532-3.

4. Rankin EA, Rankin EA Jr. Carpal tunnel syndrome: Update. J Natl Med Assoc 1995;87:193-4.

5. Gibson M. Outpatient carpal tunnel decompression without tourniquet: A simple local anaesthetic technique. Ann R Coll Surg Engl 1990;72:408-9.

6. Mirza MA, King ET Jr. Newer techniques of carpal tunnel release. Orthop Clin North Am 1996;27:355-71.

7. Baguneid MS, Sochart DH, Dunlop D, Kenny NW. Carpal tunnel decompression under local anaesthetic and tourniquet control. J Hand Surg [Br] 1997;22:322-4. authors maintain that the VAS is not sufficiently sensitive to detect a $1 \mathrm{~cm}$ difference. At $6 \mathrm{~h}$, there did appear to be increased use of analgesics and a clinically detectable difference in pain. These differences converged by $8 \mathrm{~h}$ to $10 \mathrm{~h}$ postoperatively. The present study suggests a dosing schedule for postoperative analgesics, starting analgesic pills pre-emptively at $4 \mathrm{~h}$ to $5 \mathrm{~h}$ postoperatively, which can optimize patient comfort.

Lidocaine E, bupivacaine and ropivicaine have all been established as safe and efficacious medications for this surgery (11-13). If anesthetic injection is performed in accordance with established methods (9), it has been shown to be effective. The present study did not identify any complications related to the use of adrenaline during surgery. This finding is consistent with recent publications regarding the safety of adrenaline in the hand (11). Despite recent reports, many authors still do not advocate the use of adrenaline in hand surgery (7).

\section{CONCLUSIONS}

While lidocaine E may have very slightly inferior anesthetic characteristics compared with bupivacaine/lidocaine $E$ and ropivicaine, the cost advantages (12:1 bupivacaine and 16:1 ropivacaine) make lidocaine $\mathrm{E}$ the agent of choice for carpal tunnel surgery. The authors hope that this article will further serve to dispel the unfortunate myth that adrenaline has associated risks when injected into the hand. The senior author has currently performed more than 6500 carpal tunnel releases using agents with adrenaline, and has never, on any occasion, had a complication that could be considered related to the use of adrenaline.

8. Skidmore RA, Patterson JD, Tomsick RS. Local anesthetics. Dermatol Surg 1996;22:511-22.

9. Altissimi M, Mancini GB. Surgical release of the median nerve under local anaesthesia for carpal tunnel syndrome. J Hand Surg [Br] 1988;13:395-6.

10. Brown RA, Gelberman RH, Seiler JG III, et al. Carpal tunnel release. A prospective, randomized assessment of open and endoscopic methods. J Bone Joint Surg Am 1993;75:1265-75.

11. Wilhelmi BJ, Blackwell SJ, Miller J, Mancoll JS, Phillips LG. Epinephrine in digital blocks: Revisited. Ann Plast Surg 1998;41:410-4.

12. Derkash RS, Weaver JK, Berkeley ME, Dawson D. Office carpal tunnel release with wrist block and wrist tourniquet. Orthopedics 1996;19:589-90.

13. Reitsma BJ, Bell M. Solo hand surgery. Can J Plast Surg 2005;13:145-7. 